\title{
Exploring Potential Association Between Emergency Department Crowding Status and Patients' Length of Stay at a University Hospital in Saudi Arabia
}

\author{
Mona Faisal Al-Qahtani iD \\ Fatimah Yahyia Khubrani (iD) ${ }^{2}$ \\ 'Department of Public Health, College of \\ Public Health, Imam Abdulrahman Bin \\ Faisal University, Dammam, 3144I, Saudi \\ Arabia; ${ }^{2}$ Quality Control Department, \\ Medical Center, King Fahd University of \\ Petroleum and Mineral, Dhahran, Saudi \\ Arabia
}

\begin{abstract}
Background: Emergency department (ED) crowding has been described as the most serious problem that endangers the reliability of healthcare system worldwide. The aim of this study was to explore the possible relationship of ED crowding status and length of stay in patient received care. In addition, association between LOS and other variables in relation to crowding status has been explored.
\end{abstract}

Methods: This is a retrospective cohort analysis study done by using dataset abstracted from Quadra Med Information System of patients visited emergency department of a tertiary university hospital at Eastern Province of Saudi Arabia during the period of January 1st, 2018 to December 30th, 2018. ED occupancy rates were used to define crowding status (as crowding and overcrowding), while the percentage of patient who spent in ED more than 6 hours was used to define the length of stay in ED.

Results: There were 53,309 crowded and 57,290 overcrowded presentations in ED. The median length \pm interquartile range of the length of stay for low-crowded and high-crowded conditions were $211 \pm 606$ and $242 \pm 659$ minutes, respectively. There was a significant association between ED crowding status and length of stay $(p<0.05)$.

Conclusion: The increased patients' length of stay at ED was associated with crowding status of ED. Therefore, decision-makers at ministry of health should develop and implement measures and interventions to shed light on the causes of crowding, to reduce the crowding at ED, and resolve the problem steamed from such crowding for the purpose of shorten patients' length of stay at ED.

Keywords: emergency department, crowded, length of stay, university hospital

\section{Introduction}

Crowding status of emergency department is considered a significant issue in healthcare globally. ${ }^{1}$ Emergency department crowding is viewed as a condition in which the recognized needs for emergency services surpasses available resources for patient care in the ED. ${ }^{2}$

Emergency department crowding leads to negative consequences, such as delay in patient's admission, decrease in quality of healthcare, prolonged waiting times, reduced patient satisfaction, upsurge number of patients who left without being seen, and increase medical errors. ${ }^{3-7}$

There are many causes of ED crowding have been reported in the literature. ${ }^{8}$ Among these causes is in-patient "access block", which occurs when the waiting
Correspondence: Mona Faisal Al-Qahtani Department of Public Health, College of Public Health, Imam Abdulrahman Bin Faisal University, P.O. Box 2435,

Dammam, 3144I, Saudi Arabia

Email malqahtani@iau.edu.sa 
time of ED patients requiring admission exceeds 8 hours or simply put, this refers to patient delays in accessing inpatient beds after getting admitted. ${ }^{9,10}$ These access blocks resulted in extended lengths of stay in inpatient departments and increased patient mortality. ${ }^{11}$

It has been argued that length of stay is not considered as a direct measure of ED crowding, but rather it is a significant indicator and a device/means to invigilate emergency care quality. ${ }^{12,13}$ Augmented length of stay has been correlated with unfavorable outcomes, deferrals in therapy, increase patient dissatisfaction, and lower patient safety. 3,14

Earlier studies attempted to determine the effects of ED overcrowding on patient outcome. For example, the findings of Boulain et al, Mataloni et al, Hsieh et al, AlQahtani et al, and Akhtar et al studies, respectively, ${ }^{4-7,15}$ confirmed that as long as patients stayed in EDs, death and morbidity rates increased, inter hospital stays increases, whereas healthcare personnel's conformity with treatment protocols declines. ${ }^{4-7,15}$ Other studies assessed increases in the number of patients in high-crowded and lowcrowded EDs, and found significant differences in patients' lengths of stay between those who arrived during high crowding and low crowding. However, arriving during high crowded times was not associated with overall mortality, as most assessed patients were non-urgent cases. $^{16-18}$

Another study conducted at 14 medical centers throughout Southern California revealed that total length of stay was associated with increased risks of hospitalization or death after being discharged. ${ }^{19}$ Furthermore, a retrospective study showed that during high-crowded periods in EDs, there were increases in patient admissions, particularly, elderly patients, increases in waiting times, and lengths of visits. ${ }^{20}$

In general, the literature indicates that ED overcrowding might lead to adverse impact on patient outcomes. Therefore, the associations between ED crowding status and patient outcomes should be assessed. Up to the authors' knowledge, large bulk of research on this matter has been conducted in Western countries, while limited number of similar studies have been done in Saudi Arabia. It might be anticipated that verifying the presence of associations between ED crowding, and increased lengths of stay may inspire decision-makers to report ED crowding among the top public health priorities in Saudi Arabia. Thus, the main objective of the present study is to explore the possible association between ED crowding status and patients' lengths of stay at a teaching hospital in the Eastern Province of Saudi Arabia. It is hoped that the present study will narrow that gap and yield a worth evidence on the subject, and will add to the current knowledge base about the matter of EDs crowding status and patient outcome.

\section{Methods}

This is a retrospective cohort analysis study done by using an existing dataset abstracted from Quadra Med Information System of patients who presented to the emergency department of a university hospital in the Eastern Province, Saudi Arabia during the period of 1 January 2018 to 30 December 2018. This university hospital is a mixed adult and pediatric tertiary hospital that provides services, mainly, $\mathrm{OB} / \mathrm{GYN}$, resuscitation, surgical, pediatrics, cardiac and trauma care. This hospital involves a 440 bed capacity. The emergency department includes 44 beds.

The ED occupancy rates were used to define crowding status in order to standardize comparisons of crowding states across different ED time. This measure has been widely accepted as the "crowding index". ${ }^{21}$ The percentage of patients who spent in ED more than 6 hours was used to define the length of stay in ED.

The target population includes all patients showed in the ED during the calendar year of 2018. The calendar year was divided into 4 quarters. The first quarter start from January 1st to March 31st 2018, the second quarter start from April 1st to June 30th 2018; the third quarter start from July 1st to September 30th 2018; and fourth quarter start from October 1st to December 31st 2018.

According to Cha et $\mathrm{al}^{22}$ the occupancy rate to quantify the ED crowding status was considered as low crowded if the ED occupancy rate $\leq 0.50$ and as high crowded if $1.00 \leq \mathrm{ED}$ occupancy rates. In the present study, the occupancy rate was computed based on the World Health Organization ${ }^{23}$ occupancy rate formula: Utilized bed-days x 100/available bed-days during the calendar year. Therefore, the occupancy rate for the $1 \mathrm{st}$ quarter $=2.59$, for the 2 nd quarter $=2.46$, for the $3 \mathrm{rd}$ quarter $=2.68$, and for the 4 th quarter $=3$. While the occupancy rate in this study is $>1$ for all quarters, then all quarters were considered as crowded periods. Nevertheless, based on the number of patients visits during individual quarter of the year 2018, it appears that the 2nd quarter period has the lowest number of patient visits 
( $23 \%$ of the total visits), while the 4 th quarter period has the highest number of patients visits $(29 \%$ of the total visits). Consequently, the 2 nd and 4 th quartiles would be considered as crowded and overcrowded periods for our comparison analysis.

The inclusion criteria for our study included patient presenting at the university hospital's ED during crowding and overcrowding periods of the year of 2018. While the exclusion criteria includes patients presenting at this hospital during quarters other than the 2nd and 4th quarters of the year 2018.

The patients' electronic medical records include variables such as: age, gender, nationality, triage level, and length of stay in the ED by minutes. There were $16 \%$ and $17.8 \%$ of patients spent more than 6 hours in ED during the crowded and overcrowded periods, respectively.

Ethical approval for conducting the study was secured from Imam Abdurrahman Bin Faisal University's research ethical review board (IRB-PG5-2019-03-399). Patients' written informed consent to review their medical records was not required by the ethics review board, because the data used in this study were retrieved from the patients' electronic health records found in the Quadra Med system during the year 2018 was anonymized. The patient data were collected anonymously, and the information obtained is kept confidential. This study complies with the Declaration of Helsinki. The IBM SPSS software for Mac will be used for statistical analysis. Mean and standard deviation were used to report continuous variables. Frequency and percentage were used to report categorical variables. The Mann-Whitney $U$-test and Kruskal-Wallis test were used to determine if there were any significant differences in the median length of stay by demographic variables between high- and low-crowded periods. Linear regression was conducted to identify potential association between ED crowding status and prolonged lengths of stay. The $p$-value $<0.05$ was used as cut-off values for significance.

\section{Results}

Table 1 shows the results of the Mann-Whitney $U$-test and Kruskal-Wallis test to determine if there were any significant differences in the median length of stay by demographic variables. All the variables (except for nationality in low-crowded period) were found to be significant ( $\mathrm{p}<$ 0.000 ) for both crowding options. The results showed that the length of stay was higher for male patients, especially in the high-crowding ED. In addition, patients aged 75

Table I Median of Length of Stay by Demographic Variables

\begin{tabular}{|c|c|c|c|c|}
\hline & Low Crowded Median (IQR) & $p$-value & High Crowded Median (IQR) & $p$-value \\
\hline Age & & \multirow{7}{*}{$<0.001$} & & \multirow{7}{*}{$<0.001$} \\
\hline Less than $15 Y$ & $175(535)$ & & $232(612)$ & \\
\hline $15 Y-29 Y$ & $195(602)$ & & $216(642)$ & \\
\hline $30 Y-44 Y$ & $220(628)$ & & $248(691)$ & \\
\hline $45 Y-59 Y$ & $248(649)$ & & $286(7 / 5)$ & \\
\hline $60 Y-74 Y$ & $289(623)$ & & $328(645)$ & \\
\hline More than $75 Y$ & $298(542)$ & & $344(539)$ & \\
\hline \multicolumn{4}{|l|}{ Gender } & \multirow{3}{*}{$<0.001$} \\
\hline Male & $218(622)$ & $<0.001$ & $262(68 I)$ & \\
\hline Female & $201(591)$ & & $220(628)$ & \\
\hline \multicolumn{4}{|l|}{ Nationality } & \multirow{3}{*}{$<0.001$} \\
\hline Saudi & $211(609)$ & $<0.001$ & $243(66 I)$ & \\
\hline Non-Saudi & $209(597)$ & & $237(638)$ & \\
\hline \multicolumn{4}{|l|}{ Triage } & \multirow{6}{*}{$<0.001$} \\
\hline I. Immediate & $87(160)$ & $<0.001$ & $164(290)$ & \\
\hline 2. Highly urgent ( $10 \mathrm{~min}$.) & $377(734)$ & & $378.5(1020)$ & \\
\hline 3. Urgent (30 min.) & $263(390)$ & & $279(654)$ & \\
\hline 4. Standard (60 min.) & $195(520)$ & & $237(654)$ & \\
\hline 5. Non- urgent (1 $20 \mathrm{~min})$. & $146(506)$ & & $159(492)$ & \\
\hline
\end{tabular}

Abbreviation: IQR, interquartile range. 
years and above had longer stays, regardless of crowding status, compared to other age groups. Patients classified in Triage 2 had the highest length of stay in both ED crowding status compared to other triage level patients.

Since there were significant associations $(\mathrm{p}<0.000)$ between the median length of stay at two crowding options and variables: age, gender, nationality, and triage level (Table 1), a dummy regression analysis was conducted to quantify the association between the crowding status and increases in lengths of stay. Table 2 revealed that the length of stay for female patients tend to be significantly lower than that of male patients in the lowcrowded ED. Patients whose age group between 60 and 74 and those above 75 years old tend to spend significantly $(\mathrm{p}<0.05)$ more time $(139.98$ and 88.87 , respectively,) in low crowded ED compared with that for

Table 2 Regression Analysis for Length of Stay in Low-Crowding ED

\begin{tabular}{|c|c|c|c|}
\hline & B & SE & p-value \\
\hline (Constant) & 316.779 & 22.096 & 0.000 \\
\hline Female & -43.659 & 7.769 & 0.000 \\
\hline \multicolumn{4}{|l|}{ Age categories: } \\
\hline Age 15-29 & 41.193 & 10.626 & 0.000 \\
\hline Age $30-44$ & 48.147 & 12.211 & 0.000 \\
\hline Age 45-59 & 72.959 & 15.467 & 0.000 \\
\hline Age $60-74$ & 139.988 & 21.496 & 0.000 \\
\hline Age above 75 & 88.866 & 36.619 & 0.015 \\
\hline Saudi & 21.291 & II.285 & 0.059 \\
\hline \multicolumn{4}{|l|}{ Triage levels: } \\
\hline Triage I & 247.125 & 515.317 & 0.632 \\
\hline Triage 2 & 310.777 & 137.978 & 0.024 \\
\hline Triage 3 & 157.688 & 17.525 & 0.000 \\
\hline Triage 4 & 95.762 & 9.155 & 0.000 \\
\hline \multicolumn{4}{|l|}{ Chief Complaint: } \\
\hline Abdominal and chest pain & 10.863 & 14.274 & 0.447 \\
\hline Fever & -44.882 & 16.400 & 0.006 \\
\hline Cough and cold & -18.078 & 15.476 & 0.243 \\
\hline Trauma and Cutwound & 74.284 & 18.333 & 0.000 \\
\hline
\end{tabular}

Notes: Reference categories: Gender: male; Age: $<15$ years; Nationality: non-Saudi; Triage level: triage 5; Chief complaint: patients with pregnancy issue complaints. younger patients whose age less than 15 years old. The patients' length of stay at triage 2,3 , and 4 tend to be significantly $(\mathrm{p}<0.05)$ higher by $310.8,157.7$, and 95.8 unit, respectively compared with that at triage 5 . Patients with trauma and cutwound complaint tend to spend significantly $(\mathrm{p}<0.000)$ more time $(74.3$ minutes $)$ in lowcrowd ED compared with that of patients with pregnancy issues complaints. However, the length of stay for patients with fever complaint was significantly ( $p<$ 0.05) lower than that of patients with pregnancy issue complaints.

Table 3 shows that the length of stay for female patients tend to be significantly $(\mathrm{p}<0.00)$ lower than that of male patients in the high-crowded ED. Patients whose age group between 15-29, 30-44, and 45-59 years old tend to spend significantly $(\mathrm{p}<0.05)$ less

Table 3 Regression Analysis for Length of Stay in High-Crowded ED

\begin{tabular}{|c|c|c|c|}
\hline & B & Std. Error & p-value \\
\hline (Constant) & 400.588 & 21.598 & 0.000 \\
\hline Female & -65.708 & 7.548 & 0.000 \\
\hline \multicolumn{4}{|l|}{ Age categories: } \\
\hline Age 15-29 & -78.862 & 9.844 & 0.000 \\
\hline Age $30-44$ & -74.617 & 11.661 & 0.000 \\
\hline Age $45-59$ & -38.590 & 15.172 & 0.011 \\
\hline Age $60-74$ & 29.815 & 21.079 & 0.157 \\
\hline Age above 75 & 63.262 & 38.615 & 0.101 \\
\hline Saudi & 33.604 & 11.017 & 0.002 \\
\hline \multicolumn{4}{|l|}{ Triage levels: } \\
\hline Triage I & 77.976 & 515.046 & 0.880 \\
\hline Triage 2 & -4.699 & 230.653 & 0.984 \\
\hline Triage 3 & 127.076 & 21.801 & 0.000 \\
\hline Triage 4 & 92.433 & 8.275 & 0.000 \\
\hline \multicolumn{4}{|l|}{ Chief Complaint: } \\
\hline Abdominal and chest pain & 58.347 & 15.659 & 0.000 \\
\hline Fever & -1.730 & 16.745 & 0.918 \\
\hline Cough and cold & -8.328 & 16.321 & 0.610 \\
\hline Trauma and Cutwound & 57.210 & 19.531 & 0.003 \\
\hline
\end{tabular}

Notes: Reference categories: Gender: male; Age: $<15$ years; Nationality: non-Saudi; Triage level: triage 5; Chief complaint: patients with pregnancy issue complaints. 
time (79, 75, and 39 minutes respectively) in highcrowded ED compared with that for younger patients whose age less than 15 years old. The table also revealed that the length of stay for Saudi patients tends to be significantly $(p=0.002)$ higher than that of non-Saudi. The patients' length of stay at triage 3 and 4 tends to be significantly $(\mathrm{p}<0.00)$ higher by 127 and 92 minutes, respectively, compared with that at triage 5. Patients with abdominal and chest pain as well as patients with trauma and cutwound complaint tend to spend significantly ( $\mathrm{p}<$ 0.000 ) more time (58 and 57 minutes) in high-crowded ED compared with that of patients with pregnancy issues complaints.

\section{Discussion}

The aim of this study was to identify the possible association between ED crowding status and patient outcomes. ED high crowding and patient outcomes are related in multiple ways, as demonstrated by previous studies conducted across the globe. Our findings, based on a large sample of 110,554 patients $(48.2 \%$ in a low crowded ED and $51.8 \%$ in a high crowded ED in 2018), revealed an occupancy rate of 2.46 for the low crowded ED and 3 for the high crowded ED. The latter mainly impacted length of stay, which was significantly higher than for a lowcrowded ED.

Previous studies viewed the average length of stay as an indicator for ED overcrowding. ${ }^{11,16,24}$ The median length of stay in our study was found to be higher during the high-crowded ED period (median 242 minutes vs 211 minutes in low-crowded ED). This result was also statistically significant, indicating that high crowding in the ED does have an impact on patients' average length of stay. This is in line with other studies from Taiwan and the Netherlands whose results show that an ED's high crowding results in increased lengths of stay, independent of age, sex, and time of arrival at the ED. ${ }^{17,24}$ Two more studies, one conducted in Qatar and the other in Negara, assessed length of stay, the adverse impacts on patient outcome, and their associations with a highly crowded ED, revealing that the major reason for increased length of stay at an ED was overcrowding. ${ }^{18,25}$

A study from Nepal also revealed an association between longer lengths of stay and ED high crowding, poor patient care, and decreased levels of patient satisfaction. $^{26}$

Moreover, our result shows that men tend to have longer LOS than female in both crowding time. This might be related to gender-based hazard and treatment seeking behavior as mentioned by Okoroiwu et al. ${ }^{27}$

On the other hand, there were statistically significant relationships between older and younger patients. Specifically, the lengths of stay for those aged 60-74 averaged 328 and 289 minutes respectively in both crowding status, and for those 75 years old and older, they averaged 344 and 298 minutes in both crowding periods, respectively. This result was in line with a study in Sweden that showed that the elderly are at particular risk of long lengths of stay and of revisiting the ED within 72 hours. ${ }^{28}$

This study also considered the triaging of patients, and the results showed that the largest number of triage level associated with level four (standard, 62.7\%) of the participants in a high-crowded ED with 159 minutes of LOS, and level five (Non-urgent 33.1\%) of the participants in high-crowded with 237 minutes of LOS which in line with the result of two studies came from Sweden ${ }^{16}$ and Saudi Arabia $^{29}$ indicating the LOS is increasing with less urgent cases leading to elevating crowding status.

In the current study, regression analyses showed that demographic variables (such as gender and nationality) and triage level were significant predictors of increased length of stay in both low- and high-crowded EDs. This concurred in part with several previous studies. ${ }^{25,30-32}$

\section{Limitations}

The current study had numerous limitations. First, the study was conducted in a tertiary university hospital; therefore, generalization to further health institutions should be done with carefulness. Second, this study concentrated on patient outcomes in terms of length of stay, forthcoming researches are suggested to shed light on another significant patient outcomes such as patients leaving without being seen or leaving against medical advice as a result of high crowding circumstances. Third, the research data were pulled from an electronic health data record system with incomplete data entries; accordingly, it is suggested that upcoming researches concentrated on the completeness and quality dimensions of electronic health record data. Fourth, our study investigated traditional emergency department practices such as nurse triaging, other methods such as emergency department physician triaging should be thought of in upcoming studies. Fifth, the finding of our study shows that LOS and overcrowding are associated, but it is difficult to comprehend which is the cause and which the effect. So, it is suggested that cause-effect relationship is investigate in the future 
studies. Sixth, our study used occupancy rate to defined crowding status, forthcoming studies are suggested to us other methods for analyzing the crowding in the dataset as daily or mid-daily data. Finally, this study was conducted in one institute; therefore, it is suggested that upcoming studies focused on polycentric.

\section{Recommendation}

For decision-makers at Ministry of Health, it is highly recommended to focus on creating campaign for enhancing the community awareness about the health services provided at Public Health Centers, mainly the emergency department.

For decision-makers at hospital level, it is recommended rising bed occupancy, particularly at emergency departments.

For decision-makers at human resources management departments, it is highly recommended developing workshops and on-hand training that focus on evolving and fostering the soft skills of electronic health record personnel to build their capability to enter/manage patients' data in those electronic systems used in emergency departments in full and precise approaches.

\section{Conclusion}

Effective measures to reduce crowding in emergency departments should be well planned, and they should take into account results from prior researches that shed light on the impact of emergency department crowding status on patient outcomes. Elements such as shift time, triage priority, and demographic considerations are key factors, however they have not been thought as major elements in prior researches. Therefore, upcoming studies should take into account those elements as they further investigate this important issue.

\section{Disclosure}

The authors reported no conflicts of interest for this work.

\section{References}

1. Pines JM, Griffey RT. What we have learned from a decade of ED crowding research? Acad Emerg Med. 2015;22(8):985-987. doi:10.1111/acem. 12716

2. American College of Emergency Physicians. Policy statement, approved April 2019. Available from: https://www.acep.org/globalas sets/new-pdfs/policy-statements/policy-compendium.pdf. Accessed June 19, 2020.

3. Carter EJ, Pouch SM, Larson EL. The relationship between emergency department crowding and patient outcomes: a systematic review. J Nurs Scholarsh. 2014;46(2):106-115. doi:10.1111/jnu.12055
4. Akhtar N, Kamran S, Singh R, et al. Prolonged stay of stroke patients in the emergency department may lead to an increased risk of complications, poor recovery, and increased mortality. J Stroke Cerebrovasc Dis. 2016;25(3):672-678. doi:10.1016/j. jstrokecerebrovasdis.2015.10.018

5. Hsieh CC, Lee CC, Hsu HC, Shih HI, Lu CH, Lin CH. Impact of delayed admission to intensive care units on patients with acute respiratory failure. Am $J$ Emerg $M e d . \quad 2017 ; 35(1): 39-44$. doi:10.1016/j.ajem.2016.09.066.

6. Mataloni F, Pinnarelli L, Perucci CA, Davoli M, Fusco D. Characteristics of ED crowding in the Lazio Region (Italy) and short-term health outcomes. Intern Emerg Med. 2019;14(1):109117. doi:10.1007/s11739-018-1881-3.

7. Boulain T, Malet A, Maitre O. Association between long boarding time in the emergency department and hospital mortality: a single-center propensity score-based analysis. Intern Emerg Med. 2020;15(3):479-489. doi:10.1007/s11739-019-02231-z.

8. Morley C, Unwin M, Peterson GM, Stankovich J, Kinsman L. Emergency department crowding: a systematic review of causes, consequences and solutions. PLoS One. 2018;13(8):e203316. doi:10.1371/journal.pone.0203316.

9. Forero R, Ngo H, Man N, Mountain D, Fatovich D. Response to re: impact of the four-hour national emergency access target on 30 day mortality, access block and chronic emergency department overcrowding in Australian emergency departments. Emerg Med Australas. 2019;31(1):147-148. doi:10.1111/1742-6723.13214.

10. Chan SS, Cheung NK, Graham CA, Rainer TH. Strategies and solutions to alleviate access block and overcrowding in emergency departments. Hong Kong Med J. 2015;21(4):345-352. doi:10.12809/hkmj144399.

11. Chiu IM, Lin YR, Syue YJ, Kung CT, Wu KH, Li CJ. The influence of crowding on clinical practice in the emergency department. $\mathrm{Am}$ J Emerg Med. 2018;36(1):56-60. doi:10.1016/j.ajem.2017.07.011.

12. Wiler JL, Handel DA, Ginde AA, et al. Predictors of patient length of stay in 9 emergency departments. Am J Emerg Med. 2012;30 (9):1860-1864. doi:10.1016/j.ajem.2012.03.028

13. Herring A, Wilper A, Himmelstein DU, et al. Increasing length of stay among adult visits to U.S. emergency departments, 2001-2005. Acad Emerg Med. 2009;16(7):609-616. doi:10.1111/j.15532712.2009.00428.x

14. Mentzoni I, Bogstrand ST, Faiz KW. Emergency department crowding and length of stay before and after an increased catchment area. BMC Health Serv Res. 2019;19(506). doi:10.1186/s12913-019-43424.

15. Al-Qahtani S, Alsultan A, Haddad S, et al. The association of duration of boarding in the emergency room and the outcome of patients admitted to the intensive care unit. BMC Emerg Med. 2017;17(1):34. doi:10.1186/s12873-017-0143-4.

16. Berg LM, Ehrenberg A, Florin J, Östergren J, Discacciati A, Göransson KE. Associations between crowding and ten-day mortality among patients allocated lower triage acuity levels without need of acute hospital care on departure from the emergency department. Ann Emerg Med. 2019;74(3):345-356. doi:10.1016/j.annemergmed. 2019.04.012.

17. Van Der Linden N, Van Der Linden MC, Richards JR, Derlet RW, Grootendorst DC, Van Den Brand CL. Effects of emergency department crowding on the delivery of timely care in an inner-city hospital in the Netherlands. Eur J Emerg Med. 2016;23(5):337-343. doi:10.1097/MEJ.0000000000000268

18. El Desoky S, Mashat S, Bana S, et al. Efficiency of using pediatrics emergency services and triage evaluation. Pediatr Emerg Care. 2018;34(6):417-421. doi:10.1097/PEC.0000000000000754

19. Gabayan GZ, Derose SF, Chiu VY, et al. Emergency department crowding and outcomes after emergency department discharge. Ann Emerg Med. 2015;66(5):483-492. doi:10.1016/j.annemergmed. 2015.04.009 
20. Amodio E, d'Oro LC, Chiarazzo E, et al. Emergency department performances during overcrowding: the experience of the health protection agency of Brianza. AIMS Public Health. 2018;5 (3):217-224. doi:10.3934/publichealth.2018.3.217.

21. McCarthy M, Aronsky D, Jones I, et al. The emergency department occupancy rate: a simple measure of emergency department crowding?. Ann Emerg Med. 2019;51:15-24. doi:10.1016/j. annemergmed.2007.09.003

22. Cha WC, Ahn KO, Shin SD, Park JH, Cho JS. Emergency department crowding disparity: a nationwide cross-sectional study. $J$ Korean Med Sci. 2016;31(8):1331-1336. doi:10.3346/ jkms.2016.31.8.1331.

23. World Health Organization. European health information at your fingertips. Available from: https://gateway.euro.who.int/en/indica tors/hfa_542-6210-bed-occupancy-rate-acute-care-hospitals-only/. Accessed May 05, 2020.

24. Hsu C, Liang L, Chang Y, Juang W. Emergency department overcrowding: quality improvement in a Taiwan medical center. J Formos Med Assoc. 2019;118(1):186-193. doi:10.1016/j.jfma.2018.03.008

25. Alemu GH, Negari KG, Rodamo KM, Hirigo AT. Factors associated with the length of stay in emergency departments in SouthernEthiopia. BMC Res Notes. 2019;12(1). doi:10.1186/s13104019-4271.

26. Simkhada P, Acharya S, Lama R, Dahal S, Lohala N, Thapa A. Emergency stay duration of patients in emergency department of a tertiary care hospital in Nepal: a descriptive cross-sectional study. J Nepal Med Assoc. 2020;58(222). doi:10.31729/jnma.4806
27. Okoroiwu H, Uchendu K, Essien R. Causes of morbidity and mortality among patients admitted in a tertiary hospital in southern Nigeria: a 6 year evaluation. PLoS One. 2020;15:e0237313. doi:10.1371/journal.pone.0237313

28. Chouihed T, Wargon M, Yordanov Y. Are delays in emergency departments really harmless?. Eur J Emerg Med. 2019;26(6):462. doi:10.1097/mej.0000000000000620.

29. Alyasin A, Douglas C. Reasons for non-urgent presentations to the emergency department in Saudi Arabia. Int Emerg Nurs. 2014;22 (4):220-225. doi:10.1016/j.ienj.2014.03.001.

30. Chaou C, Chen H, Chang S, et al. Predicting length of stay among patients discharged from the emergency department-using an accelerated failure time model. PLoS One. 2017;12(1):e0165756. doi:10.1371/journal.pone.0165756

31. Casalino E, Wargon M, Peroziello A, et al. Predictive factors for longer length of stay in an emergency department: a prospective multicentre study evaluating the impact of age, patient's clinical acuity and complexity, and care pathways. Emerg Med J. 2014;31 (5):361-368. doi:10.1136/emermed-2012-202155

32. Phinyo P, Patumanond J. Indicators for an extended length of stay in the emergency service unit of a Thai community hospital: a multi-level analysis. Epidemiol Biostat Public Health. 2020;17.
Open Access Emergency Medicine

\section{Publish your work in this journal}

The Open Access Emergency Medicine is an international, peerreviewed, open access journal publishing original research, reports, editorials, reviews and commentaries on all aspects of emergency medicine. The manuscript management system is completely online and includes a very quick and fair peer-review system, which is all easy to use. Visit http://www.dovepress.com/testimonials.php to read real quotes from published authors. 